\title{
The impact of number mismatch and passives on the real-time processing of relative clauses*
}

\author{
CARLA CONTEMORI \\ Pennsylvania State University, USA
}

AND

THEODOROS MARINIS

School of Psychology E Clinical Language Sciences, University of Reading, $U K$

(Received 31 Fanuary 2012-Revised 4 October 2012-Accepted I 2 February $20 \mathrm{I}_{3}$ First published online 17 Fune 2013)

\section{ABSTRACT}

Language processing plays a crucial role in language development, providing the ability to assign structural representations to input strings (e.g., Fodor, I 998). In this paper we aim at contributing to the study of children's processing routines, examining the operations underlying the auditory processing of relative clauses in children compared to adults. English-speaking children $(6 ; 0-8$; I I ) and adults participated in the study, which employed a self-paced listening task with a final comprehension question. The aim was to determine (i) the role of number agreement in object relative clauses in which the subject and object NPs differ in terms of number properties, and (ii) the role of verb morphology (active vs. passive) in subject relative clauses. Even though children's off-line accuracy was not always comparable to that of adults, analyses of reaction times results support the view that children have the same structural processing reflexes observed in adults.

[*] This research was supported by the Short Term Scientific Mission scholarship, awarded to the first author by COST Action ISo804 'Language impairment in a multilingual society’, and by the 20 I I Marica De Vincenzi postdoctoral fellowship, awarded to the first author by the Marica De Vincenzi Foundation Onlus. We thank Adriana Belletti, Giuliano Bocci, Vicky Chondrogianni, Maria Teresa Guasti and Luigi Rizzi for helpful comments. Thanks to the COST Action ISo804, 'Language impairment in a multilingual society' and the Marica De Vincenzi Foundation Onlus, who made the data collection possible. All errors are ours. Address for correspondence: Pennsylvania State University - Psychology, ${ }_{4} \mathrm{E}$ Thomas Building, State College, Pennsylvania I680 I, USA. e-mail : carla.contemori@gmail.com 


\section{INTRODUCTION}

In this paper we investigate the on-line comprehension of Subject (SR) and Object (OR) relative clauses in English-speaking children compared to adults. As illustrated in (I), in a SR the element that is relativized (the boy) is the subject of the verb within the relative clause (is hugging), whereas in an OR, as in (2), the relativized element is the object of the verb.

(I) SR: This is the boy that is hugging the mother

(2) OR: This is the boy that the mother is hugging _

Off-line comprehension studies showed that while children correctly produce SRs as in (I) very early (two to three years of age; Labelle, I990; among others), ORs appear later (Friedmann \& Novogrodsky, 2004; a.o.), and children comprehend them at chance level until the age of four to five (Correa, I 995; de Villiers, Tager-Flusberg, Hakuta \& Cohen, I979; a.o.).

In contrast, on-line studies comparing the comprehension of relative clauses in children and adults illustrated that children from the age of four use the same parsing mechanism as adults, and that the differences that emerge are generally due to children's limited working memory capacity, slower speed of lexical retrieval, or limited lexicon (Hestvik, Schwartz, Tornyova \& Datta, 2005 ; Love, I 997; Roberts, Marinis, Felser \& Clahsen, 2007). These observations support a CONTINUITY HYPOTHEsis of language acquisition, according to which, from the age of four, language processing changes quantitatively over the course of the child's development, but the principles that govern it are present from early on and in a similar form to that in adults (Crain \& Thornton, I998; Crain \& Wexler, I999; Fodor, I 998 ; a.o.).

In the present paper, we analyze the processing of SRs and ORs in children and adults, manipulating some morphological aspects of the nouns and verbs involved in these structures, and focusing on which features children rely on during interpretation. In particular, we investigate the role of number agreement in children's processing of ORs, and the role of active and passive verb morphology in their processing of SRs.

For ORs, recent studies showed that the processing difficulty with ORs can be reduced by manipulating the lexical category, the animacy properties or the gender/number features of the subject (the mother, in (2)) or the object NP (the boy, in (2)) of the relative clause in both children and adults (for adults: Gordon, Hendrick \& Johnson, 200I, 2004; Mak, Vonk \& Schriefers, 2002, 2006; Traxler, 2002; Warren \& Gibson, 2002, 2005; for children: Adani, 2008; Adani, van der Lely, Forgiarini \& Guasti, 20ıо; Arosio, Guasti \& Stucchi, 20I I; Belletti, Friedmann, Brunato \& Rizzi, 2012; Friedmann, Belletti \& Rizzi, 2009). In two off-line comprehension studies, Adani (2008) and Adani et al. (2010) showed that Italian- and English-speaking children aged five to nine were more accurate in 
interpreting ORs in which the two NPs differed in terms of number features, as in (4), compared to (3) (Adani, 2008).

(3) Match: The lion-SG that the cat-SG is touching is sitting on the ground

(4) Mismatch: The lions-PL that the crocodile-SG is touching are sitting on the ground

So far, the manipulation of features in children's comprehension of ORs has been tested using off-line tasks (Adani, 2008; Adani et al., 20 Io; Belletti et al., 2012). It is, therefore, unclear whether or not the advantage in sentences with a mismatch between the head of the OR and the subject within the relative clause is due to on-line facilitation or whether it represents a late off-line effect. We address this issue by investigating number morphology in ORs by means of an on-line comprehension task, with both children and adults.

In our study we also investigate the role of passive morphology in SRs, as in (6), compared to active SRs (5), and ORs (7).

(5) SR active: This is the boy that is hugging the mother

(6) SR passive: This is the boy that is being hugged by the mother

(7) OR: This is the boy that the mother is hugging

Active SRs are acquired very early by children across languages, around the age of $2 ; 6-3$; (Correa, I995; de Villiers et al., I979; Friedmann \& Novogrodsky, 2004; Sheldon, I974; Tavakolian, I98I ; a.o.). In contrast, SRs with passives appear in child speech around the age of five to six (elicited production: Contemori \& Belletti, 20I3; Jensen de Lopez, Sundahl Olsen \& Chondrogianni, 2012), with passives displaying a more complex verbal structure which is not fully mastered by children until a late stage of language development (Horgan, i 978; Maratsos, Fox, Becker \& Chalkley, I 985 ; a.o.).

For children, there are no studies illustrating the on-line processing of SRs with passives (for adults, see Rodhe \& Gibson, 2003). Nonetheless, we know that Italian children aged 6;OI-8; I are significantly more accurate in the off-line comprehension of SRs with passives than ORs (Contemori \& Belletti, 2013). In our study, we examine the role of passive verbal morphology in children's comprehension of SRs, compared to active SRs and ORs. The aim is twofold. First of all, previous on-line studies on the comprehension of actives and passives in simple monoclausal sentences (e.g., The cow chased the goat vs. The cow is chased by the goat) showed contrasting results (Marinis, 2007; Marinis \& Saddy, 2013; Stromswold, Eisenband, Norland \& Ratzan, 2002). Therefore, by comparing active and passive SRs, we aim to clarify how children process actives and passives compared to adults. Second, as previous results suggest that passive SRs are easier to comprehend for children than ORs (Contemori \& Belletti, 20I3), 
we compare the overall reaction times for passive SRs and ORs in children and adults to clarify the role of complexity of passive SRs and ORs.

In our research we take into consideration two syntactic structures that are acquired late by children (ORs with matching of number features; passive SRs), and we manipulate the noun and verb morphology to create syntactic structures that are comprehended more accurately by children (i.e., ORs with a mismatch of number features, and active SRs that children aged $6 ;$ o I-8; I c comprehend above chance but not yet like adults). Then, we analyze the on-line reaction times for the harder and easier syntactic structures, comparing children's and adults' processing routines. Our goal is to investigate if the facilitation effects found with children in off-line tasks (number feature match vs. mismatch; active vs. passive; passive SRs vs. ORs) are driven by a qualitative difference between the processing systems of the two populations, and to clarify the nature of the late full mastery of SRs with passives and ORs in children.

The study is divided into three parts. In the first part, we test ORs by means of a self-paced listening task and we manipulate the number properties of the NPs, addressing the question of how and to what extent children find ORs with subject and object NPs that are different in terms of number features easier to comprehend. In the second part, with the same on-line task, we investigate how SRs with active or passive verb morphology are processed by children. In the third part, we compare the processing of passive SRs and ORs in children and adults.

\section{Object relative clauses and the role of number features in production and comprehension}

Previous studies have shown that the difficulty that adults and children experience with ORs can be reduced by manipulating the lexical category (e.g., noun, pronoun, etc.) or the number/gender features of the subject and object NPs in the OR. In adults, a facilitation effect has been observed when the subject and object NPs of the OR differed in terms of animacy properties (e.g., The movie (inanimate) that the director (animate) watched received a prize; see Mak et al., 2002, 2006; Traxler, 2002).

Furthermore, adults found it easier to interpret sentences in which the two NPs differed from each other in terms of lexical category, with one of the NPs being in turn a proper noun, a pronoun, or a quantified expression (e.g., It was the lawyer (description) who we (pronoun)/Dan (proper noun) avoided at the party; see Gordon et al., 2001, 2004; Warren \& Gibson, 2002, 2005).

Recent findings on children acquiring Hebrew (Belletti et al., 2012; Friedman et al., 2009), English (Adani, 2008), and Italian (Adani et al., 2010; Arosio et al., $20 \mathrm{II}$; Belletti et al., 2012) showed that the degree of 
complexity of ORs in children's comprehension seems to be related to the type of subject and object NP involved in the relative clause. In particular, when the subject and the object NPs differ in terms of lexical category (e.g., a wh-operator, an impersonal arbitrary pro subject; Friedmann et al., 2009), number features (Adani, 2008; Adani et al., 2010), gender features (Adani, 2008; Adani et al., 2010; Belletti et al., 2012), or animacy properties (Arosio et al., 20I I), children experience a lower degree of difficulty in comprehension.

Friedmann et al. (2009) conducted a study with Hebrew children aged $3 ; 07-5 ; 0$, and observed that free relatives, as in (9), and ORs with impersonal pro, as in (Io), were easier for Hebrew children to comprehend than ORs with two full lexically restricted NPs, i.e., those NPs in which a nominal expression is introduced by a wh-word (e.g., which cow in (10)) or a determiner (e.g., the cow in (9)), as exemplified in (8). Hence, the composition of the lexical elements involved in the filler-gap relation was found to be crucial (Friedmann et al., 2009).

$$
\begin{gathered}
\text {.. the chicken that the cow kisses } \\
\text { D NP.. }
\end{gathered}
$$

(9) ... who (the one) that the boy is spraying

$$
\text { Wh ... R ... D NP ... }
$$

(Iо) ... the boy who (someone/they) kiss him

$\mathrm{D} \quad \mathrm{NP} \ldots \mathrm{R} \ldots$ pro $\ldots$ arb ... pronoun

Friedmann et al. (2009) interpreted the children's results as an effect of intervention, as described by the Relativized Minimality principle (RM) first proposed by Rizzi (I 990).

( і г) $\ldots \mathrm{X} \ldots \mathrm{Z} \ldots \mathrm{Y} \ldots$

Given the configuration in (II), RM predicts that a local structural relation cannot hold between $\mathrm{X}$ and $\mathrm{Y}$ if $\mathrm{Z}$ is of the same structural type as $\mathrm{X}$, and is thus a potential bearer of the same local relation (Rizzi, I990). Friedmann et al. (2009) proposed that in the configuration of a relative clause such as (2), the head of the relative clause (e.g., the boy) and the intervening subject (e.g., the mother) share some crucial morphosyntactic feature (in the case at issue, they both contain a lexical restriction, i.e., they both carry the feature $[+\mathrm{NP}])$. This creates a configuration in which the dependency between the head of the relative clause (the object, e.g., the boy) and its gap within the relative clause (i.e., the position where the object is interpreted, that the mother is hugging _ _) is blocked for children, so that they cannot properly comprehend this structure. Within the same approach, Belletti et al. (2012) added that, besides $[+\mathrm{NP}]$, there are other features which are crucial for determining whether or not an OR will be difficult to comprehend for children. In particular, in Belletti et al., the crucial features 
triggering intervention in child language are those that play an active morphosyntactic role, hence those that count as syntactic attractors for movement, such as gender in Hebrew (Belletti et al., 2012) and number in Italian and English (Adani, 2008; Adani et al., 2010). According to Belletti et al., if there is no featural distinction between the gender/number features of two NPs, children have more difficulty in establishing the filler-gap dependency, due to the presence of a lexical subject acting as an intervener and disruptor, and they cannot attribute the correct agent/patient theta roles (e.g., 'Who did what to whom?').

Particularly relevant for the aim of our study are the results of Adani (2008). By means of a picture-matching task, Adani tested a group of English-speaking children aged $6 ; 03-8 ; 07$ on the off-line comprehension of a set of ORs, in which the subject and object NPs differed in terms of number features, as in (12)-(13).

(I2) Match: The lion-SG that the cat-SG is touching is sitting on the ground

(I3) Mismatch: The lions-PL that the crocodile-SG is touching are sitting on the ground

Adani (2008) found that English-speaking participants were more accurate in comprehending the conditions of Mismatch than those of Match, and showing that the off-line comprehension of English-speaking children is affected by the sensitivity to number information available on the head of the relative and the subject NP. However, the study by Adani did not provide any information about the on-line processing of these sentences.

The match and mismatch of number features have also been examined in studies on interference in language production (Bock \& Eberhard, I993; Eberhard, I997; Haskell \& MacDonald, 2003; a.o.). By means of sentence completion tasks under time pressure, interference can occur when a noun is situated in the vicinity of the subject-verb agreement relation and imposes its number on the verb, triggering an effect of attraction, with errors such as (I4) being more likely to occur in production than errors such as (I5). For our study, it is particularly relevant that the attraction effects observed in subject-verb agreement are stronger by plural intervening elements (e.g., flights in ( I4)), than by singular ones (e.g., flight in (г5)) (Bock \& Eberhard, I993; Eberhard, I997; Haskell \& MacDonald, 2003 ; a.o.).

(I4) The helicopter for the flights is/*are safe

(I 5) The helicopters for the flight are/*is safe

To account for these findings, it was suggested that plural NPs are better attractors because they are 'marked' for number as compared to the default singular value (Bock \& Eberhard, I993). 
On the basis of previous studies on attraction, we expect to find a difference in the processing of plural NPs, compared to singular NPs, due to the MARKEDNEss of plurality (i.e., plural is morphologically marked with respect to singular, bearing number morphology), and independently of the matching or mismatching of number features in the OR.

In our study on the matching and mismatching of number features in ORs, we first aim at replicating Adani's (2008) off-line results, showing that children's interpretation improves when there is a distinction in the internal structure of the NPs involved in the OR. Furthermore, adding reaction time data, we aim at examining how children's comprehension process unfolds in ORs, how singular NPs are processed in comparison to plural NPs, and which features children use to assign structural representations to the incoming material. For the comparison between children and adults, we consider previous studies on the on-line comprehension of relative clauses in children (Arosio et al., 20 I I Felser, Marinis \& Clahsen, 2003; Hestvik et al., 2005; Love, I 997; Roberts et al., 2007), and we predict that children may show longer reaction times than adults. We also expect that children will show the same pattern of performance in terms of the reaction times, for instance with shorter reaction times for plural compared to singular NPs. This would indicate no qualitative differences between the children's and adults' processing routines.

In terms of off-line comprehension, we expect that children will be overall less accurate than adults on ORs (Sheldon, I977, a.o.). Furthermore, adopting the approach by Friedmann et al. (2009) and Belletti et al. (2012), we assume that the presence of the intervener subject in ORs will cause a disruption of the dependency between the head of the relative and its gap, leading to a lower accuracy for ORs in children compared to adults. We also predict that number features will play a role in the computation of the similarity between the head of the relative and the intervener. Therefore, we expect that children will perform more accurately on the off-line comprehension of ORs with mismatching number features compared to ORs with matching number features (Adani, 2008; Adani et al., 2010). Based on Friedmann et al. (2009) and Belletti et al. (2012), we also predict that the disruption of the filler-gap dependency will emerge in off-line comprehension, and we will investigate if this effect will also emerge in on-line processing of ORs.

Finally, based on the findings on interference and attraction (Bock \& Eberhard, I993; Eberhard, I997; Haskell \& MacDonald, 2003; a.o.), we expect to find a difference in the processing of plural and singular NPs, with plural NPs being processed faster than singular ones. This effect would be due to the MARKEDNESS of plurality and would emerge independently of the OR condition (matching-mismatching). 
Subject relative clauses and the role of passives vs. actives

Active SRs appear very early in child speech across languages, around the age of 2;6-3;0 (Correa, I995; de Villiers et al., ı 979; Friedmann \& Novogrodsky, 2004; Sheldon, I974; Tavakolian, I98ı; a.o.). In contrast, SRs with passives emerge later, around the age of 5 ;0-6;0 (Contemori \& Belletti, 2013; Jensen de Lopez et al., 2012), with the syntactic structure of passives being more complex than that of actives (e.g., Horgan I978; Maratsos et al., I985; Sudhalter \& Braine, I985; a.o.). Passives have been investigated in children in previous studies by means of on-line techniques (Marinis, 2007; Marinis \& Saddy, 2013 ; Stromswold et al., 2002). On-line studies on the comprehension of passives in children analyzed actives and passives in simple monoclausal sentences (e.g., The cow chased the goat vs. The cow is chased by the goat), showing contrasting results (Marinis, 2007; Marinis \& Saddy, 2013; Stromswold et al., 2002).

Stromswold et al. (2002) tested preschool (3;01-4;08), school-aged (4;09-7;04) children, and adults on active/passive sentences such as (16) and (I7), by means of a sentence-picture matching task while recording their eye-movements.

(i6) The girl was pushed by the boy

( I 7) The girl was pushing the boy

From the eye-movement data, Stromswold et al. (2002) showed that, while adults decided which picture matched the sentence at the past participle, children looked at the matching picture only after the end of the sentence. On the basis of these results, Stromswold et al. concluded that children do not seem to use the same cues as adults on-line, but rather adopt a strategy according to which the first NP is the agent, and they interpret the passive morphology of the verb off-line after the end of the sentence.

In a self-paced listening study comparing monolingual and L2 children, Marinis (2007) and Marinis and Saddy (2013) tested English-speaking children aged six to eight. In the task, participants saw one picture and then listened to an active or a passive sentence segment by segment, deciding whether or not the picture matched the sentence, as exemplified in ( 18)-( 19).

(I 8) I think/that/the zebra/was kissing/the camel/at the zoo/last Monday (matching or mismatching picture)

( I 9) I think/that/the camel/was kissed/by the zebra/at the zoo/last Monday (matching or mismatching picture)

Marinis (2007) and Marinis and Saddy (2013) found longer reaction times when a passive sentence did not match a picture displayed on a computer screen in the two segments containing the verb and the $b y$-phrase, respectively 
(e.g., /was kissed/by the zebra /). The authors proposed that in a situation of mismatch between the sentence and the picture, when the passive verb was encountered and it did not match children's expectations compared to the picture, children made a reanalysis, which was reflected in the longer RTs for the mismatch conditions. Marinis, and Marinis and Saddy, concluded that children aged six to eight are sensitive to passive morphology on-line, and are capable of rapid integration and early thematic role assignment.

The results on the interpretation of passives by Marinis (2007) and Marinis and Saddy (2013) contrast with those of Stromswold et al. (2002). However, the two studies differ in three main aspects, i.e., the age of the children, the design of the study (eye-tracking vs. self-paced listening; one picture vs. two pictures), and the length of the sentences used in the experiment.

In Study 2 of the present paper, we investigate the on-line processing of passives and actives with a self-paced listening task (as in Marinis, 2007; Marinis \& Saddy, 2013), measuring off-line comprehension by means of two pictures (as in Stromswold et al., 2002). We test English-speaking children of a similar age as Marinis, and Marinis and Saddy, examining for the first time how children process passives in subject relative clauses that children are known to use productively from the age of five to six (as shown by Contemori \& Belletti, 2013; Jensen de Lopez et al., 2012). The aim is to shed light on the real-time processing of actives and passives, addressing the debate on whether children can use passive verbal morphology on-line (Marinis, 2007; Marinis \& Saddy, 2013; Stromswold et al., 2002) in the presence of additional complexity (i.e., relative clause with subject extraction). As suggested by Marinis, and Marinis and Saddy, in the segment-by-segment analysis we predict longer reaction times for passives compared to the active counterpart in both children and adults as a result of the thematic role assignment. We also expect children to be slower overall in processing than adults, but to use the same processing pattern.

\section{Passive subject relative clauses and object relative clauses}

The production of passives in SRs in comparison to ORs has recently been investigated in an elicitation context (for Italian: Belletti \& Contemori, 20ıо; Contemori \& Belletti, 20ı3; for Danish; Jensen de Lopez et al., 20I2). Belletti and Contemori, and Contemori and Belletti, elicited SRs and ORs in Italian-speaking children aged 3;4-8; ro and adults. These studies showed that ORs were typically avoided by both adults and (older) children, and the most dominant avoidance strategy for an OR was to transform it into a SR with a passive, as illustrated in (20)-(2 I). Similar results were observed with Danish children of similar age $(5 ; 0-8 ; 2)$ by Jensen de Lopez et al., Contemori and Belletti also showed that Italian adult speakers 
resorted to passives in the same elicitation context, preferring to use SRs with passives in (almost) all cases.

(20) Target answer: (Vorrei essere) il bambino che la mamma/ragazza abbraccia

'(I would rather be) the boy that the mother/girl hugs'

(2 I) Copular passive: Il bambino che viene abbracciato dalla mamma

'The child that is hugged by the mother' (B.G. 6;3)

Following Friedmann et al. (2009), Contemori and Belletti (2013) suggested that the use of passive SRs when an OR is expected is a strategy adopted by both adults and children to avoid a more complex OR. As the configuration of an OR involves the intervention of the subject NP between the head of the relative and its gap, ORs would be naturally avoided by adults and children by using passive SRs, where no intervention of the subject occurs. Belletti and Contemori (2010) and Contemori and Belletti (2013) assume a derivation of passives in the terms proposed by Collins (2005) and Belletti (2009), in which intervention is avoided altogether, as illustrated in (22):

(22) Il bambino che viene $[\mathrm{vP}$ abbracciato $<$ il bambino $>$ ] da $[\mathrm{vP}$ la mamma $<\mathrm{VP}>$ ]

According to Collins (2005) and Belletti (2009), the derivation of passives involves the operation of SMUGGLING, which consists of taking a chunk of the verb phrase containing the verb (e.g., abbracciato) and the direct object (e.g., il bambino), and moving it across the vP-internal subject DP (e.g., la mamma). As illustrated in (22), given the derivation by SMUGGLING, the intervention of the subject DP (e.g., la mamma) is avoided altogether in passive sentences, and the movement of the VP-chunk allows movement of the object (e.g., il bambino) into the relative head position, with no intervention of the subject.

The fact that ORs are more complex than SRs with passives due to intervention is also demonstrated by Contemori and Belletti (2013) with an off-line picture-matching task. Contemori and Belletti showed that Italian-speaking children aged 6;0I-8; I were significantly more accurate in comprehending SRs with passives, than ORs.

Passive SRs have been investigated by means of a self-paced reading study in English adults by Rodhe and Gibson (2003). Interestingly, Rodhe and Gibson showed that reaction times were overall shorter for SRs with passives than for ORs, showing that SRs with passives were processed faster than ORs in adults.

To date, there are no studies illustrating the on-line processing of SRs with passives in children compared to ORs. The present research aims to fill 
this gap by analyzing how children process SRs with passives in real time in comparison to ORs. The aim is to test the approach by Belletti (2009) and Contemori and Belletti (2013), and to observe if a difference between the two structures emerges in the processing of children and adults. The experimental design used in the present research does not allow a direct comparison between the reaction times of SRs with passives and ORs segment-by-segment, because the words in each segment are not comparable in the two sentence types. Therefore, we compare the reaction times of adults and children for the total length of ORs and passive SRs, similarly to Rodhe and Gibson (2003). The aim of such an analysis is to examine the advantage/disadvantage of processing one structure over the other. We assume that passive SRs are structurally less complex than ORs due to the absence of intervention (Contemori \& Belletti, 20 I3; Belletti, 2009) and we predict that the listening RTs for passive SRs will be shorter overall than for ORs, independently of the matching or mismatching of number features in the OR. We also expect that the effect will emerge in adults (see Rodhe \& Gibson, 2003), but might not be detectable in children who will have longer overall RTs compared to adults.

\section{THE PRESENT STUDIES}

This research consists of two studies. In Study $\mathbf{I}$, we investigate the comprehension of right-branching ORs in real time, replicating the match and mismatch number conditions investigated by Adani (2008). The aim is to show how children's comprehension process unfolds in ORs, how singular and plural NPs are processed, and how number features are used by children to assign structural representations to the incoming material. In Study 2, we focus on right-branching subject relative clauses with active and passive morphology in the same experimental groups. The aim is to investigate on-line sensitivity to passive verbal morphology compared to actives in the context of a $\mathrm{SR}$ in children and adults. In the comparison between Study I and 2, we analyze the on-line results for passive SRs and ORs by comparing the reaction times of the whole sentences in adults and children. The aim is to examine if there is any advantage in the processing of passive SRs compared to ORs.

In Studies I and 2, we predict that children will show longer reaction times than adults, but that they will show the same processing pattern as adults in both ORs with matching and mismatching number features and in active/passive SRs. This means that, like adults, children should take longer in the match than mismatch condition for ORs, and on passive than active SRs. In the comparison between Studies I and 2, we predict an advantage in the processing of passive SRs over ORs, due to the lower complexity of the former over the latter (Belletti, 2009; Contemori \& Belletti, 2013). 
In our studies we adopt a self-paced listening task, which provides a step-by-step measure of sentence processing. The rationale is that increased listening times to a particular segment (relative to the same segment in a control condition) indicates a relatively higher processing difficulty at that point in the sentence (for adults, see Ferreira, Henderson, Anes, Weeks \& McFarlane, I996, a.o.; for children, see Felser et al., 2003, a.o.).

\section{STUDY I}

METHOD

\section{Participants}

Seventeen monolingual English-speaking adults and thirty-four monolingual English-speaking children took part in the study. The adults were I9;0-25;O $(M=2 \mathrm{I} ; S D=4.5)$; they were students at the University of Reading and were granted credits for their participation. The children were 6;0I-8; I (mean age: 7;06; SD: 0.10) and they were randomly selected from state and private schools in Reading (UK).

\section{Materials}

We designed a self-paced listening task that provides a segment-by-segment measure of processing time. Two experimental factors on ORs were manipulated, Number and Matching, and each factor had two levels: Number (Singular vs. Plural) and Matching (Match vs. Mismatch). A total of four conditions was tested, as shown in (23)-(26), and we used ten sentences per condition. This gave rise to forty experimental sentences.

(23) Plural-Plural (PP): These are/the cows/that the goats/are pushing/in the field/on Thursday

(24) Plural-Singular (PS): These are/the cows/that the goat/is pushing/in the field/on Thursday

(25) Singular-Plural (SP): This is/the cow/that the goats/are pushing/in the field/on Thursday

(26) Singular-Singular (SS): This is/the cow/that the goat/is pushing/in the field/on Thursday

Two of the four conditions, i.e., (23) and (26), display a match in number features between the head of the relative and the subject of the relative clause, and two conditions, i.e., (24) and (25), display a mismatch.

The OR in (23) is an example of an OR with a plural head (the cows) and a plural subject (the goats), whereas (26) is an example of a match condition with a singular head (the cow) and a singular subject within the relative clause (the goat). In the mismatch condition in (24) the head is in the plural and the subject of the relative clause is in the singular, whereas in the 
mismatch condition in (25) the head of the relative is in the singular and the subject is in the plural.

All sentences were semantically reversible, and nouns in subject and object NPs were all animal names, and matched in size, in order to prevent any size-bias interpretation. Four transitive verbs were selected (chase, kiss, stroke, push) and each of them was used for two sets of ORs. The nouns and verbs used in the sentences had an age of acquisition of five years or below based on the MRC Psycholinguistic Database (Wilson, i 988).

Apart from the forty experimental sentences, this experiment also included twelve pseudo-fillers (the experimental items of Study 2) and twenty-eight filler-sentences of similar complexity. The experimental and filler sentences were digitally recorded by two native speakers of English in a noise-proof sound booth. The sentences were segmented using Adobe Audition, with the slashes indicating the segmentation boundaries.

Each sentence was matched with two pictures, one of which appeared on the left side of the screen and one of which appeared on the right side. In the SS condition, one of the pictures showed a figure carrying out an action on another, while the other picture showed the same figures with the roles reversed. For the PP condition, similar pictures showed a pair of the same characters. For the mismatch conditions (PS-SP), one character was carrying out an action on two other figures and the other picture showed the same figures with the roles reversed. Figure I shows an example of each of the four conditions with the two corresponding pictures.

The sentences were pseudo-randomized so that items belonging to the same condition or containing the same nouns/verbs were counterbalanced in two blocks and did not appear consecutively. Each participant encountered both blocks in one session. Picture position on the screen was also counterbalanced, so that for half of the questions the correct picture appeared on the left side of the screen, and for the other half of the questions the correct picture appeared on the right side.

\section{Procedure}

The participants were tested individually in a quiet room - the adults in one of the university labs and the children in a quiet room in their school. The participants first saw two pictures on a laptop's computer screen. Upon pressing the space bar on the laptop, the first segment of the sentence was presented. Participants continued to listen to the sentence segmentby-segment by pressing the space bar of the laptop, while the two pictures remained on the computer screen. The auditory sentences were presented through headphones. The end of each sentence was signalled by an acoustic tone. After the acoustic tone, the two pictures appeared on the screen each marked by a number $(\mathrm{I}, \mathrm{O})$. The participants had to choose the picture that 
(1) Plural-Plural (PP): These are the cows that the goats are pushing in the field on Thursday
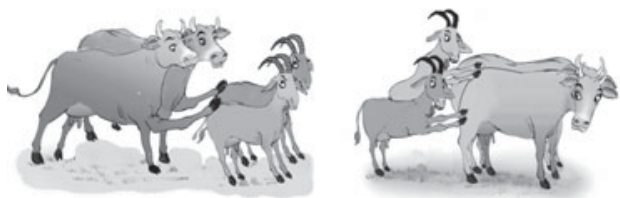

(2) Plural-Singular (PS): These are the cows that the goat is pushing in the field on Thursday
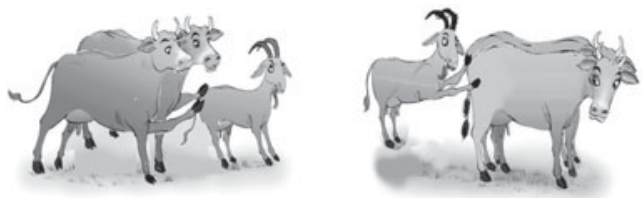

(3) Singular-Plural (SP): This is the cow that the goats are pushing in the field on Thursday
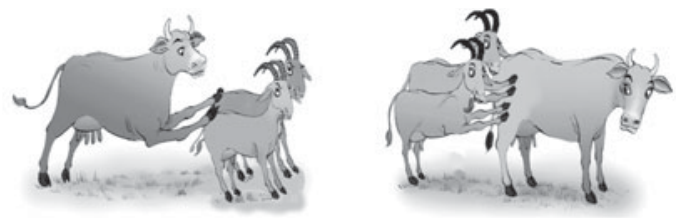

(4) Singular-Singular (SS): This is the cow that the goat is pushing in the field on Thursday
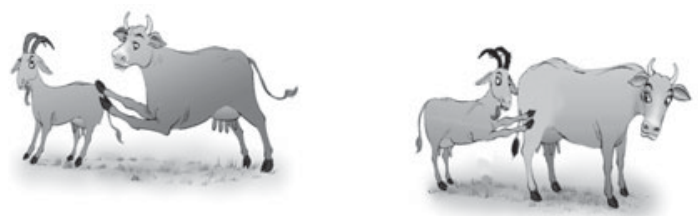

Fig, I: Sample material for Study I.

matched the sentence by pressing either ' $\mathrm{I}$ ' or ' $O$ ' on the keyboard. The keys ' I' and ' $O$ ' were chosen as they are equidistant from the space bar. The ' $I$ ' is on the left side of the keyboard and always corresponded to the left picture, whereas ' $O$ ' is on the right side of the keyboard and corresponded to the right picture. Each response key was highlighted with a brightcoloured sticker. 
TABLE I. Off-line accuracy data in percentage, number, mean, and standard deviation

\begin{tabular}{llll}
\hline Conditions & & Adults & Children \\
\hline PP & Total (\%) & 99 & 78 \\
& Number & $\mathrm{I} 69 / \mathrm{r} 70$ & $264 / 340$ \\
& Mean (\%) & $9 \cdot 94$ & $7 \cdot 65$ \\
& SD & $0 \cdot 24$ & $\mathrm{I} \cdot 94$ \\
PS & Total (\%) & 99 & 87 \\
& Number & $\mathrm{I} 69 / \mathrm{r} 70$ & $296 / 340$ \\
& Mean (\%) & $9 \cdot 94$ & $8 \cdot 50$ \\
& SD & $0 \cdot 24$ & $\mathrm{I} \cdot 48$ \\
SP & Total (\%) & 99 & 86 \\
& Number & $\mathrm{I} 69 / \mathrm{r} 70$ & $291 / 340$ \\
& Mean (\%) & $9 \cdot 94$ & $8 \cdot 32$ \\
& SD & $0 \cdot 24$ & $\mathrm{I} \cdot 77$ \\
SS & Total (\%) & 98 & 79 \\
& Number & $\mathrm{I} 67 / \mathrm{r} 70$ & $269 / 340$ \\
& Mean (\%) & $9 \cdot 82$ & $7 \cdot 79$ \\
& SD & $0 \cdot 39$ & $\mathrm{I} \cdot 90$ \\
\hline
\end{tabular}

At the beginning of the experiment, there was a practice block of nine trials. This was to familiarize participants with the task. The practice items had constructions similar to the ones used in the experiment. E-prime was used to present the stimuli and to record RTs from the onset of each segment until each key press. The experiment was administered to both children and adults in one session, lasting about 20-30 minutes.

\section{RESULTS}

We conducted two types of analysis: an analysis of the accuracy in the off-line comprehension question and an analysis of the on-line listening reaction times. For both sets of data we used repeated measures ANOVAs with Group (children, adults) as a between-subjects factor, and Number (singular, plural) and Match (match, mismatch) as within-subjects factors per subjects $\left(\mathrm{F}_{\mathrm{I}}\right)$ and per items $\left(\mathrm{F}_{2}\right)$. Interactions were followed using pairwise comparisons with Bonferroni correction. We first present the accuracy data and then the R'T data.

\section{Analyses of accuracy}

Table I shows the accuracy of the two groups in the four experimental conditions. The repeated measures ANOVA showed a main effect of Group $\left(F_{\mathrm{I}}(\mathrm{I}, 49)=28,920, p<\cdot 000 \mathrm{I}, \eta p^{2}=\cdot 37\right.$ I $; F_{2}(\mathrm{I}, \mathrm{I} 8)=6$ I 3,47 I , 
$\left.p<\cdot 000 \mathrm{I}, \quad \eta p^{2}=\cdot 97 \mathrm{I}\right)$, Matching $\left(F_{\mathrm{I}}(\mathrm{I}, 49)=5,844, \quad p<\cdot 0 \mathrm{I} 9, \quad \eta p^{2}=\cdot{ }_{\text {I }}\right.$ 7 $;$ $F_{2}($ I I 8$)=8,7$ I $\left.6, p<\cdot 009, \eta p^{2}=\cdot 326\right)$, and an interaction between Group and Matching $\left(F_{\mathrm{I}}(\mathrm{I}, 49)=4, \mathrm{I} 55, \quad p<\cdot 047, \quad \eta p^{2}=.078 ; \quad F_{2}(\mathrm{I}, \mathrm{I} 8)=7,295\right.$, $p<$ - $\left.{ }_{5} 5, \eta p^{2}=\cdot 288\right)$. Pairwise comparisons using Bonferroni correction showed that children were more accurate in the conditions with mismatching number than in the matching conditions $\left(F_{\mathrm{I}}(\mathrm{I}, 33)=\mathrm{I} 0,208\right.$, $p<\cdot 003, \eta p^{2}=\cdot 236 ; F_{2}($ I, I 8$)=8$, I $8, p<\cdot 0$ I $\left.9, \eta p^{2}=\cdot 474\right)$, but there was no difference between match and mismatch in adults. An effect of Group emerged in the comparison between the two match conditions $\left(F_{\mathrm{I}}(\mathrm{I}, 49)=30,226, \quad p<\cdot 000 \mathrm{I}, \quad \eta p^{2}=\cdot 382 ; \quad F_{2}(\mathrm{I}, \mathrm{I} 8)=244,654, \quad p<\cdot 000 \mathrm{I}\right.$, $\left.\eta p^{2}=\cdot 93 \mathrm{I}\right)$ and between the two mismatch conditions $\left(F_{\mathrm{I}}(\mathrm{I}, 49)=\mathrm{I} 8, \mathrm{I} 23\right.$, $p<\cdot 000$ I,$\left.\eta p^{2}=\cdot 270 ; F_{2}(\mathrm{I}, \mathrm{I} 8)=434,3 \mathrm{I} 2, p<\cdot 000 \mathrm{I}, \eta p^{2}=\cdot 960\right)$ and no other main effects or interactions were found.

\section{Analyses of reaction times}

Inaccurate responses of both adults and children were eliminated prior to the analyses of RTs. To control for the length of each segment, raw RTs were transformed into residual RTs. Residual RTs were calculated by subtracting the participants' RTs from the length of each segment. Residual RT data were screened for negative values, extreme values, and outliers (see Marinis, 2010; Ratcliff, I 993).

The average length of the final consonant $-s$ for plural NPs, together with the silence at the end of the segment, was approximately $80 \mathrm{~ms}$. As RTs below $-80 \mathrm{~ms}$ indicated that participants did not hear the final consonant, we eliminated all negative RTs of less than $-80 \mathrm{~ms}$ (approximately $2 \cdot 6 \%$ of the data for children and $\mathbf{I} \cdot 9 \%$ for adults). Furthermore, when a value of less than $-80 \mathrm{~ms}$ was present in the third segment, the entire trial was deleted (approximately $0.9 \%$ of the data for children and $0.9 \%$ for adults). This was because the third segment contained the subject of the relative clause in either singular (SS-PS condition) or plural (PP-SP condition) form, which was crucial for the correct interpretation of the sentence.

Extreme values and outliers were defined on the basis of SPSS boxplots. Extreme values, defined in SPSS as values more than three times the interquartile range from the rest of the scores, were deleted (approximately $\mathrm{I} \cdot 2 \%$ of the data for children and I $\%$ for adults). Outliers, defined as values more than $I_{5} 5$ times the interquartile range from the rest of the scores, were replaced with recalculated mean values per subject per condition (approximately $3 \cdot 4 \%$ of the data for children and $\mathrm{I} \cdot 6 \%$ for adults).

Table 2 and Figures 2 and 3 show the RTs of the two groups in milliseconds.

Each segment was analyzed separately with a repeated-measures ANOVA. In all segments there was a main effect of Group, reflecting longer 
TABLE 2. Mean RTs and Standard Deviation of children and adults for each segment and condition

Segments

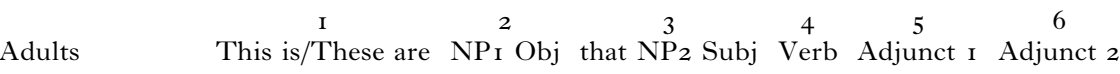

\begin{tabular}{|c|c|c|c|c|c|c|c|}
\hline \multirow[t]{2}{*}{ PP } & Mean & I 84 & 246 & I 35 & 256 & 207 & 244 \\
\hline & $\mathrm{SD}$ & 92 & $7 \mathrm{I}$ & 78 & 93 & 94 & I 3 I \\
\hline \multirow[t]{2}{*}{ PS } & Mean & I 94 & 234 & 222 & 262 & I99 & 299 \\
\hline & $\mathrm{SD}$ & 87 & 77 & 56 & I IO & 93 & 126 \\
\hline \multirow[t]{2}{*}{ SP } & Mean & I 96 & 317 & I 4 I & 244 & I 93 & 239 \\
\hline & $\mathrm{SD}$ & 70 & 67 & 97 & 96 & 86 & I I I \\
\hline \multirow[t]{2}{*}{ SS } & Mean & I 87 & $29 \mathrm{I}$ & 200 & 265 & 201 & 232 \\
\hline & $\mathrm{SD}$ & 90 & 69 & 9I & 98 & 76 & 87 \\
\hline
\end{tabular}

Children $\quad$ This is/These are $\stackrel{2}{\mathrm{NP}_{\mathrm{I}}}$ Obj that $\stackrel{3}{\mathrm{NP}_{2}}$ Subj $\stackrel{4}{4} \underset{5}{5} \frac{6}{6}$ Adjunct I Adjunct 2

\begin{tabular}{|c|c|c|c|c|c|c|c|}
\hline \multirow[t]{2}{*}{ PP } & Mean & 397 & 472 & 410 & 605 & 479 & 483 \\
\hline & SD & 125 & I 56 & I 49 & I $8 \mathrm{I}$ & I4 I & I 35 \\
\hline \multirow[t]{2}{*}{ PS } & Mean & 425 & $48 \mathrm{I}$ & 474 & $5^{6} \mathrm{I}$ & 478 & $50 \mathrm{I}$ \\
\hline & SD & IIO & I 44 & 127 & I I 3 & I 34 & I 49 \\
\hline \multirow[t]{2}{*}{ SP } & Mean & 373 & 554 & 378 & $5^{8 \mathrm{I}}$ & 467 & 465 \\
\hline & SD & 136 & $I_{5}$ I & 123 & 162 & I4 I & II 8 \\
\hline \multirow[t]{2}{*}{ SS } & Mean & 398 & 522 & $45 \mathrm{I}$ & 575 & $45^{8}$ & 469 \\
\hline & SD & I I 3 & 109 & I 2 I & I 52 & I 27 & I 28 \\
\hline
\end{tabular}

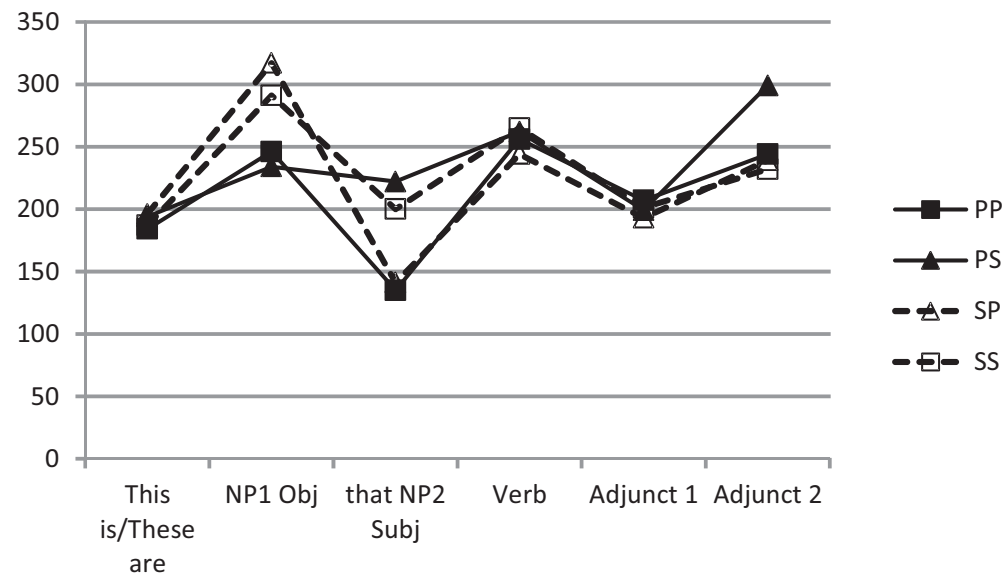

Fig. 2. Mean RTs of adults for each segment and condition. 


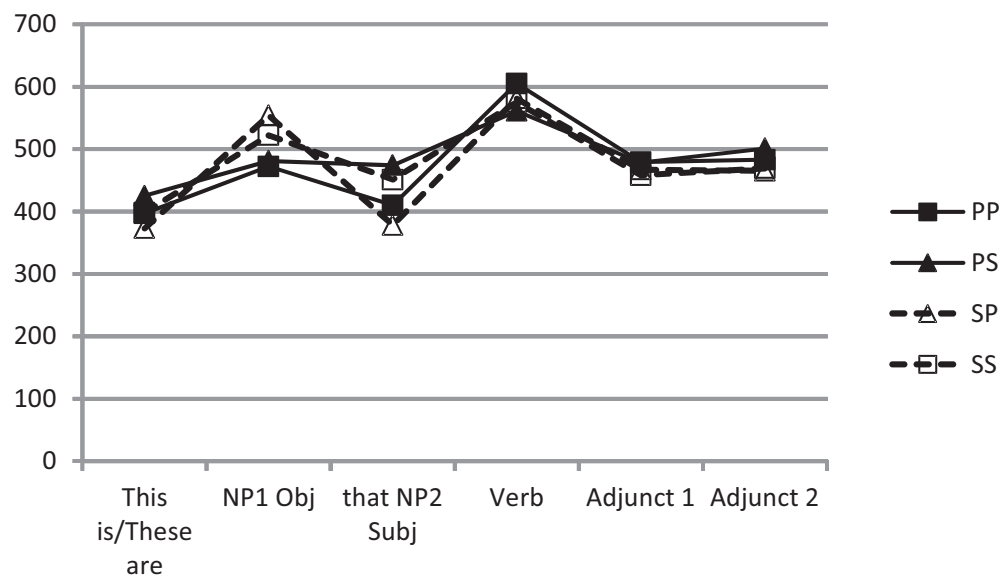

Fig. 3. Mean RTs of children for each segment and condition.

RTs in children compared to adults [Segment I: $\left(F_{\mathrm{I}}(\mathrm{I}, 50)=49,2 \mathrm{I} 3\right.$, $\left.p<\cdot \circ 00 \mathrm{I}, \eta p^{2}=\cdot 496 ; F_{2}(\mathrm{I}, \mathrm{I} 8)=55,603, p<\cdot 000 \mathrm{I}, \eta p^{2}=\cdot 755\right)$; Segment 2 : $\left(F_{\mathrm{I}}(\mathrm{I}, 50)=52,240, \quad p<\cdot 000 \mathrm{I}, \quad \eta p^{2}=\cdot 5 \mathrm{II} ; \quad F_{2}(\mathrm{I}, \mathrm{I} 8)=272,5 \mathrm{I} 2, p<\cdot 000 \mathrm{I}\right.$, $\left.\eta p^{2}=\cdot 938\right) ; \quad$ Segment $3: \quad\left(F_{\mathrm{I}}(\mathrm{I}, 50)=70,339, \quad p<\cdot 000 \mathrm{I}, \quad \eta p^{2}=._{5} 8_{5}\right.$; $\left.F_{2}(\mathrm{I}, \mathrm{I} 8)=\mathrm{I}_{3} 6,235, p<\cdot 000 \mathrm{I}, \eta p^{2}=\cdot 883\right)$; Segment $4:\left(F_{\mathrm{I}}(\mathrm{I}, 50)=94,44 \mathrm{I}\right.$, $\left.p<\cdot 000 \mathrm{I}, \eta p^{2}=\cdot 654 ; F_{2}(\mathrm{I}, \mathrm{I} 8)=584,608, p<\cdot 000 \mathrm{I}, \eta p^{2}=\cdot 970\right)$; Segment 5 : $\left(F_{\mathrm{I}}(\mathrm{I}, 50)=80,34 \mathrm{I}, \quad p<\cdot 000 \mathrm{I}, \quad \eta p^{2}=.6 \mathrm{I} 6 ; \quad F_{2}(\mathrm{I}, \mathrm{I} 8)=238,770, \quad p<\cdot 000 \mathrm{I}\right.$, $\left.\eta p^{2}=\cdot 930\right) ; \quad$ Segment $\quad 6: \quad\left(\mathrm{F}_{\mathrm{I}}(\mathrm{I}, 50)=58,578, \quad p<\cdot 000 \mathrm{I}, \quad \eta p^{2}=.540\right.$; $F_{2}($ I, I 8$)=$ I I0,456, $p<\cdot 000$ I,$\left.\left.\eta p^{2}=\cdot 860\right)\right]$.

In Segment 2, we obtained an effect of Number $\left(F_{\mathrm{I}}(\mathrm{I}, 50)=36,796\right.$, $\left.p<\cdot 000 \mathrm{I}, \eta p^{2}=\cdot 424 ; F_{2}(\mathrm{I}, \mathrm{I} 8)=23,555, p<\cdot 000 \mathrm{I}, \quad \eta p^{2}=\cdot 567\right)$ reflecting longer RTs in singular compared to plural NPs. Segment 3 showed an interaction between Matching and Number $\left(F_{\mathrm{I}}(\mathrm{I}, 50)=43,786, p<\cdot 000 \mathrm{I}\right.$, $\left.\eta p^{2}=\cdot 467 ; \quad F_{2}(\mathrm{I}, \mathrm{I} 8)=44,084, \quad p<\cdot 000 \mathrm{I}, \quad \eta p^{2}=.7 \mathrm{I0}\right)$, indicating that matching affected singular and plural nouns in a different way. The pairwise comparisons showed that there was a significant difference in the following pairs: PP shorter than PS $\left(F_{\mathrm{I}}\left(\mathrm{I}, 5_{\mathrm{I}}\right)=24,669, p<\cdot 000 \mathrm{I}\right.$, $\left.\eta p^{2}=.326 ; F_{2}\left(\mathrm{I}, \mathrm{I}_{9}\right)=7, \mathrm{I}_{5}, p<\cdot \mathrm{OI}_{5}, \eta p^{2}=.272\right)$, PP shorter than SS $\left(F_{\mathrm{I}}(\mathrm{I}, 5 \mathrm{I})=\mathrm{I} 0,99 \mathrm{I}, \quad p<\cdot 002, \quad \eta p^{2}=\cdot{ }_{\mathrm{I}} 77 ; \quad F_{2}(\mathrm{I}, \mathrm{I} 9)=\mathrm{I}_{2,005}, \quad p<\cdot 003\right.$, $\left.\eta p^{2}=\cdot 387\right)$, SP shorter than PS $\left(F_{\mathrm{I}}(\mathrm{I}, 5 \mathrm{I})=5 \mathrm{I}, 857, p<\cdot 000 \mathrm{I}, \eta p^{2}=.504\right.$; $\left.F_{2}(\mathrm{I}, \mathrm{I} 9)=23,203, \quad p<\cdot 000 \mathrm{I}, \quad \eta p^{2}=\cdot 550\right), \quad$ and $\mathrm{SP}$ shorter than SS $\left(F_{\mathrm{I}}(\mathrm{I}, 5 \mathrm{I})=38 \cdot 338, \quad p<\cdot 000 \mathrm{I}, \quad \eta p^{2}=\cdot 429 ; \quad F_{2}(\mathrm{I}, \mathrm{I} 9)=\mathrm{I0}, 404, \quad p<\cdot 004\right.$, $\left.\eta p^{2}=\cdot 354\right)$.

Finally, in Segment 6, we obtained a main effect of Number in the analysis per subject $\left(F_{\mathrm{I}}(\mathrm{I}, 50)=6,295, p<\cdot 0_{\mathrm{I}}, \eta p^{2}=\cdot_{\mathrm{I}} \mathrm{I}_{2} ; F_{2}(\mathrm{I}, \mathrm{I} 8)=2, \mathrm{I} 80\right.$, 
$p=\cdot{ }_{5} 57, \eta p^{2}=\cdot{ }_{108}$, reflecting longer RTs in sentences with the head of the $\mathrm{OR}$ in the plural compared to the singular.

\section{INTERIM DISCUSSION}

The accuracy results show that English-speaking adults comprehend the four types of ORs equally well. In contrast, children are significantly less accurate than adults in all conditions, as shown by the main effect of Group. This result confirms previous off-line studies on ORs (de Villiers et al., r979; Sheldon, I974; Tavakolian, I981; a.o.), showing that up to the age of eight, the comprehension of ORs in English-speaking children is not yet adult-like.

Furthermore, the main effect of Matching obtained in our analysis suggests that children are more accurate in comprehending ORs with mismatch (SP-PS) than ORs with match (SS-PP). This is in line with the study of Adani (2008) that tested the off-line comprehension of centre-embedded ORs with matching and mismatching number features, showing that English TD children (age: $6 ; 03-7 ; \circ 3,7 ; \circ 9-8 ; \circ 7$ ) comprehended conditions SP and PS more accurately than those conditions where subject and object NPs had the same number value (PP and SS).

The analyses of RTs revealed a main effect of Group in all segments, suggesting that children are overall processing sentences slower than adults. This supports previous studies that reported generally slower processing in children compared to adults (e.g., Felser et al., 2003). However, despite the difference between the two groups in terms of processing speed, there were no qualitative differences in the way the two groups processed the sentences in real time.

Both groups showed an effect of plurality, with shorter RTs when a plural NP is encountered as the NP-head of the relative clause (Segment 2) or the NP-subject within the relative clause (Segment 3), compared to a singular NP (Segment 2: RTs in PP and PS are shorter than SP and SS; Segment 3: RTs in PP and SP are shorter than PS and SS). In addition, both groups showed a late effect of Number in Segment 6, with shorter RTs for conditions with a plural head (PP, PS) than conditions with a singular head (SS, SP). Because Segment 6 is the final segment of the sentence, this effect could indicate a wrap-up effect.

\section{STUDY 2}

METHOD

\section{Participants}

The same participants from Study I also participated in Study 2. 

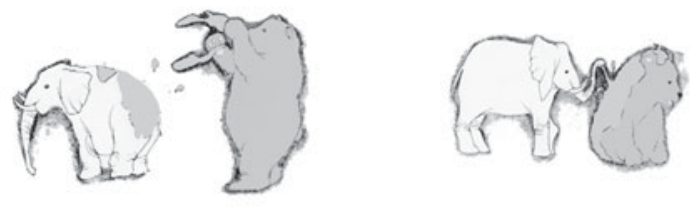

(28) SR passive: This is / the bear / that is being painted / by the elephant / in the woods / on Sunday
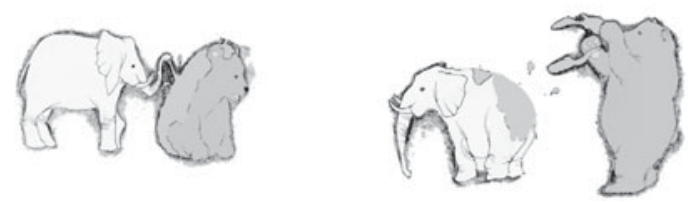

Fig. 4: Sample material for Study 2.

\section{Materials}

Study 2 addresses the processing of SRs with actives vs. passives, as shown in $(27)$ and $(28)$ :

(27) Subject relative active (SR active)

This is/the bear/that is painting/the elephant/in the woods/on Sunday

(28) Subject relative passive (SR passive)

This is/the bear/that is being painted/by the elephant/in the woods/on Sunday

We created six sentences for each of the two conditions. All sentences were semantically reversible and the noun phrases were always animate. Nouns in subject and object NPs were all animal names matched in size in order to prevent any size-bias interpretation. Six transitive verbs were chosen (paint, comb, kick, pull, bite, spray) and each of them was used for a set of two sentences. Verbs and nouns had an age of acquisition of five years or below based on the MRC Psycholinguistic Database (Wilson, I988).

The sentences were recorded and segmented according to the segmentation shown above with the slashes indicating segmentation boundaries.

The twelve experimental items were pseudo-randomized with the forty experimental items of Study I and twenty-eight fillers of similar complexity. The twenty-eight fillers were active and passive declaratives, 
TABLE 3. Off-line accuracy data in percentage, number, mean, and standard deviation

\begin{tabular}{llll}
\hline Conditions & & Adults & Children \\
\hline SR active & Total (\%) & I00 & 92 \\
& Number & I02/102 & I93/210 \\
& Mean (\%) & 6 & 5.51 \\
SD & 0 & 0.73 \\
SR passive & Total (\%) & 97 & 85 \\
& Number & $99 / \mathrm{IO}$ & $\mathrm{I} 78 / 2 \mathrm{I} 0$ \\
& Mean (\%) & 5.82 & 5.09 \\
& SD & 0.38 & $\mathrm{I} \cdot 08$ \\
\hline
\end{tabular}

introduced by I think that (e.g.: I think that the bear is chasing the camel in the field in the morning/I think that the bear is being chased by the camel in the field in the morning). Experimental items and fillers were divided into two blocks of trials. Each participant was presented with both lists of trials.

Each sentence was matched with two pictures, one of which appeared on the left side of the screen and one of which appeared on the right side. In both active and passive conditions, one of the pictures showed a figure carrying out an action on another, while the other picture showed the same figures with the roles reversed. Figure 4 shows an example of each condition with the two corresponding pictures.

\section{Procedure}

Study 2 had the same procedure as Study I.

\section{RESULTS}

As in Study I, we conducted two types of analysis: an analysis of the accuracy in the off-line comprehension question and an analysis of the on-line listening reaction times. For both sets of data we used a repeated-measures ANOVAs with Group (children, adults) as a between-subjects factor, and Sentence Type (active, passive) as within-subjects factor per subjects ( $\left.F_{I}\right)$ and per items $\left(\mathrm{F}_{2}\right)$.

Interactions were followed using pairwise comparisons with Bonferroni correction. We will first present the accuracy data and then the RT data.

\section{Analyses of accuracy}

Table 3 shows the accuracy of the two groups in the SRs with active and passive verb conditions. The ANOVA revealed a main effect of 
TABLE 4. Mean RTs and Standard Deviation of children and adults for each segment and condition

\begin{tabular}{|c|c|c|c|c|c|c|c|}
\hline \multirow[b]{2}{*}{ Children } & & \multicolumn{6}{|c|}{ Segments } \\
\hline & & $\begin{array}{c}\text { I } \\
\text { This is }\end{array}$ & $\begin{array}{c}2 \\
\mathrm{NPI}_{\mathrm{I}}\end{array}$ & $\begin{array}{l}3 \\
\text { that } \mathrm{V} / \text { that } \\
\text { is being } \mathrm{V}\end{array}$ & $\begin{array}{c}4 \\
\mathrm{NP}_{2} / \mathrm{by} \\
\mathrm{NP}_{2}\end{array}$ & $\begin{array}{c}5 \\
\text { Adjunct I }\end{array}$ & $\begin{array}{c}6 \\
\text { Adjunct } 2\end{array}$ \\
\hline SR active & $\begin{array}{l}\text { Mean } \\
\text { SD }\end{array}$ & $\begin{array}{l}503 \\
133\end{array}$ & $\begin{array}{l}542 \\
157\end{array}$ & $\begin{array}{l}448 \\
\text { I } 53\end{array}$ & $\begin{array}{l}583 \\
\text { I } 75\end{array}$ & $\begin{array}{l}397 \\
\text { I } 22\end{array}$ & $\begin{array}{l}430 \\
167\end{array}$ \\
\hline SR passive & $\begin{array}{l}\text { Mean } \\
\text { SD }\end{array}$ & $\begin{array}{l}486 \\
\text { I I } 7\end{array}$ & $\begin{array}{l}5 \mathrm{I} 4 \\
200\end{array}$ & $\begin{array}{l}376 \\
\text { I } 34\end{array}$ & $\begin{array}{l}548 \\
\text { I } 55\end{array}$ & $\begin{array}{l}486 \\
\text { I } 54\end{array}$ & $\begin{array}{l}5 \circ 3 \\
343\end{array}$ \\
\hline Adults & & This is & $\mathrm{NP}_{\mathrm{I}}$ & $\begin{array}{l}3 \\
\text { that } \mathrm{V} / \text { that } \\
\text { is being } \mathrm{V}\end{array}$ & $\begin{array}{c}4 \\
\mathrm{NP}_{2} / \mathrm{by} \\
\mathrm{NP}_{2}\end{array}$ & $\begin{array}{c}5 \\
\text { Adjunct I }\end{array}$ & $\begin{array}{c}6 \\
\text { Adjunct } 2\end{array}$ \\
\hline SR active & $\begin{array}{l}\text { Mean } \\
\text { SD }\end{array}$ & $\begin{array}{r}263 \\
52\end{array}$ & $\begin{array}{r}26 I \\
6 I\end{array}$ & $\begin{array}{r}\text { I } 58 \\
62\end{array}$ & $\begin{array}{r}229 \\
96\end{array}$ & $\begin{array}{r}\text { I } 28 \\
85\end{array}$ & $\begin{array}{l}204 \\
\text { I } 14\end{array}$ \\
\hline SR passive & $\begin{array}{l}\text { Mean } \\
\text { SD }\end{array}$ & $\begin{array}{r}256 \\
66\end{array}$ & $\begin{array}{l}20 \mathrm{I} \\
\mathrm{I} 12\end{array}$ & $\begin{array}{r}\text { I } 56 \\
83\end{array}$ & $\begin{array}{l}190 \\
103\end{array}$ & $\begin{array}{r}213 \\
92\end{array}$ & $\begin{array}{l}242 \\
\text { I I } 6\end{array}$ \\
\hline
\end{tabular}

Group $\quad\left(F_{\mathrm{I}}(\mathrm{I}, 50)=\mathrm{II}, \mathrm{I} 42, \quad p<\cdot 002, \quad \eta p^{2}=\cdot{ }_{\mathrm{I}} 82 ; \quad F_{2}(\mathrm{I}, \mathrm{I} \mathrm{O})=\mathrm{I}_{0} 78,358\right.$, $\left.p<\cdot 000 \mathrm{I}, \eta p^{2}=\cdot 99 \mathrm{I}\right)$, reflecting higher accuracy in adults compared to children, and a main effect of Sentence type $\left(F_{\mathrm{I}}\left(\mathrm{I}, 5^{\circ}\right)=4,452, p=\cdot 040\right.$, $\left.\eta p^{2}=.082 ; F_{2}(\mathrm{I}, \mathrm{IO})=4,737, p=.055, \eta p^{2}=.32 \mathrm{I}\right)$, reflecting higher accuracy in actives compared to passives, but there was no interaction between the two variables.

\section{Analyses of reaction times}

As in Study I, we calculated residual RTs per segment per condition and we followed the same trimming procedures. Negative RTs of less than $-80 \mathrm{~ms}$ were deleted (approximately $0.6 \%$ of the data for children and $2.5 \%$ for adults). Furthermore, the average length of the final past participle suffix -ed for passive trials together with the silence at the end of the segment was approximately $80 \mathrm{~ms}$. Therefore, we eliminated all trials with a negative RT of less than $-80 \mathrm{~ms}$ (approximately $0.5 \%$ of the data for children and $3.6 \%$ for adults) in the third segment, which contained the past participle and was therefore crucial for the correct interpretation of the sentence.

Extreme values and outliers were defined on the basis of SPSS boxplots, as in Study I. Extremes values were eliminated (approximately $0.7 \%$ of the data for children and $2 \cdot 9 \%$ for adults) and outliers were replaced with recalculated mean values per subject per condition (approximately $\mathrm{I} \cdot 2 \%$ of 


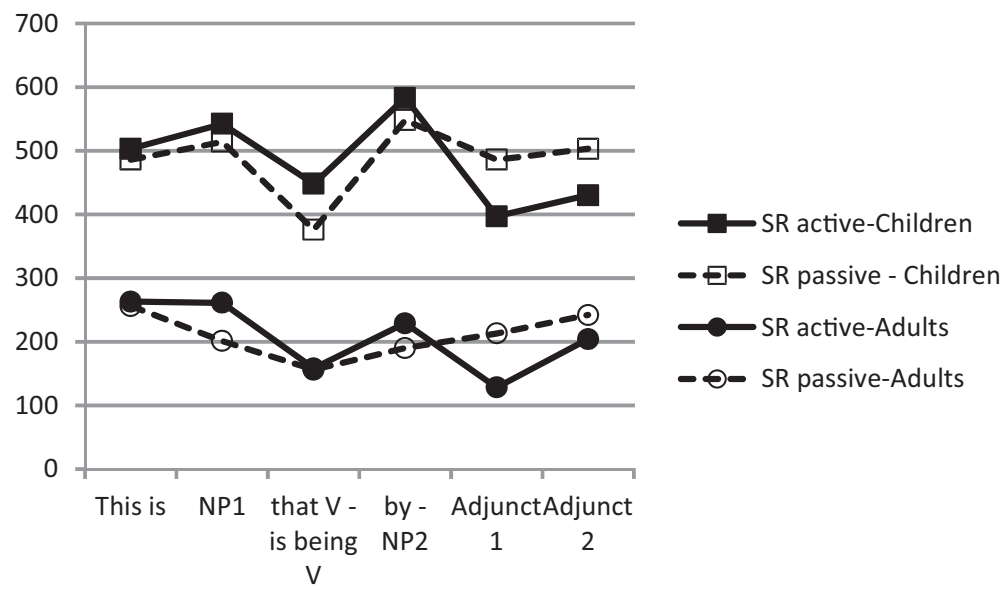

Fig. 5. Mean RTs of children and adults for each segment and condition.

the data for children and $3 \%$ for adults). Table 4 and Figure 5 show the RTs of the two groups in ms.

Each segment was analyzed separately. All segments showed a main effect of Group, reflecting longer RTs in children compared to adults [Segment I : $\left(F_{\mathrm{I}}(\mathrm{I}, 50)=63,899, p<\cdot 000 \mathrm{I}, \eta p^{2}={ }_{5} 6 \mathrm{I} ; F_{2}(\mathrm{I}, \mathrm{IO})=\mathrm{I}_{29,205}\right.$, $\left.p<\cdot 000 \mathrm{I}, \eta p^{2}=\cdot 928\right)$; Segment $2:\left(F_{\mathrm{I}}(\mathrm{I}, 50)=48,42 \mathrm{I}, p<\cdot 000 \mathrm{I}, \eta p^{2}=\cdot 492\right.$; $\left.F_{2}(\mathrm{I}, \mathrm{I} \mathrm{O})=82,023, p<\cdot 000 \mathrm{I}, \eta p^{2}=\cdot 89 \mathrm{I}\right) ;$ Segment $3:\left(F_{\mathrm{I}}(\mathrm{I}, 50)=58,677\right.$, $\left.p<\cdot 000 \mathrm{I}, \eta p^{2}=\cdot 540 ; F_{2}(\mathrm{I}, \mathrm{IO})=\mathrm{I04}_{259}, p<\cdot 000 \mathrm{I}, \eta p^{2}=\cdot 912\right)$; Segment 4 : $\left(F_{\mathrm{I}}(\mathrm{I}, 50)=92,624, \quad p<\cdot 000 \mathrm{I}, \quad \eta p^{2}=.649 ; \quad F_{2}(\mathrm{I}, \mathrm{I} \mathrm{O})=80,847, \quad p<\cdot 000 \mathrm{I}\right.$, $\left.\eta p^{2}=\cdot 890\right) ; \quad$ Segment $5: \quad\left(F_{\mathrm{I}}(\mathrm{I}, 50)=66,858, \quad p<\cdot 000 \mathrm{I}, \quad \eta p^{2}=.572\right.$; $F_{2}(\mathrm{I}, \mathrm{I}$ O $)=$ I 7I $\left.708 ; p<\cdot 000 \mathrm{I}, \eta p^{2}=\cdot 945\right)$; Segment $6:\left(F_{\mathrm{I}}(\mathrm{I}, 50)=\mathrm{I} 6, \mathrm{I} 67\right.$, $\left.\left.p<\cdot 000 \mathrm{I}, \eta p^{2}=\cdot 248 ; F_{2}(\mathrm{I}, \mathrm{I} \mathrm{O})=49,840, p<\cdot 000 \mathrm{I}, \eta p^{2}=\cdot 833\right)\right]$.

In Segment 2 there was also a main effect of Sentence type in the analysis per subject $\left(F_{\mathrm{I}}(\mathrm{I}, 50)=5, \mathrm{I} 64, p<\cdot 027, \eta p^{2}=\cdot 094 ; F_{2}(\mathrm{I}, \mathrm{IO})=\cdot 053\right.$, $\left.p=\cdot 823, \eta p^{2}=.005\right)$, reflecting longer RTs in actives compared to passives. Segment 3 also showed a main effect of Sentence type in the per subject analysis $\left(F_{\mathrm{I}}(\mathrm{I}, 50)=4,560, p<\cdot 038, \eta p^{2}=\cdot 084 ; F_{2}(\mathrm{I}, \mathrm{I} \mathrm{O})=2 \cdot 247, p=\cdot{ }_{1} 6_{5}\right.$, $\left.\eta p^{2}=\cdot{ }_{1} 8_{3}\right)$, and an interaction between Sentence type and Group approached significance $\left(F_{\mathrm{I}}(\mathrm{I}, 50)=3,939, \quad p=\cdot 053, \quad \eta p^{2}=.073\right.$; $F_{2}($ I, IO $)=\cdot 4$ I $\left.3, p=\cdot 535, \eta p^{2}=\cdot 40\right)$. The Pairwise comparisons showed that the main effect of Sentence type in Segment 3 was only present in the children's group $\left(F_{\mathrm{I}}(\mathrm{I}, 34)=9 \cdot 903, p<\cdot 003, \eta p^{2}=\cdot 226 ; F_{2}(\mathrm{I}, \mathrm{I} \mathrm{O})=104 \cdot 259\right.$, $\left.p<\cdot 000 \mathrm{I}, \eta p^{2}=\cdot 9 \mathrm{I} 2\right)$, and not in adults.

Segment 5 showed a main effect of Sentence type $\left(F_{\mathrm{I}}(\mathrm{I}, 50)=24,990\right.$, $\left.p<\cdot 000 \mathrm{I}, \eta p^{2}=\cdot 333 ; F_{2}(\mathrm{I}, \mathrm{IO})=30,6 \mathrm{I} 8, p<\cdot 000 \mathrm{I}, \eta p^{2}=\cdot 754\right)$, reflecting longer RTs in passives compared to actives. The same effect was attested in 
the per items analysis of Segment $6\left(F_{\mathrm{I}}(\mathrm{I}, 49)=\mathrm{I} \cdot 625, p<\cdot 208, \eta p^{2}=\cdot 032\right.$; $F_{2}\left(\right.$ I , IO) $=8,742, p<\cdot \circ$ I $\left.4, \eta p^{2}=\cdot 466\right)$.

\section{INTERIM DISCUSSION}

The analysis of accuracy results showed that children are overall significantly less accurate than adults, and that SRs with passives are comprehended by both groups less accurately than SRs with actives. For children, this is in line with the literature on the acquisition of passives, according to which English-speaking typically developing children make errors in the comprehension and production of passives until the age of six to seven (Borer \& Wexler, I987; Fox \& Grodzinsky, I998; Horgan, I978; Maratsos et al., I985; Marinis, 2007; Marinis \& Saddy, 2013; Stromswold et al., 2002; a.o.).

The analysis of RTs revealed two main findings. First, similarly to Study I, children are overall slower than adults in the processing of both active and passive SRs. The second main finding is that there is a difference in the on-line processing of the two conditions in both groups. Both groups showed shorter RTs in passives vs. actives in Segment 2 in the analysis per subjects. However, at this point in the sentence, both sentence types have the same structure, and no syntactic difference suggests one interpretation or the other. Therefore, it is unclear why there is a difference between the two conditions in this segment. Given that this difference occurs only in the per subject analysis and the effect size is small, we will not discuss this effect any further because it is not a reliable effect.

In Segment 3, a main effect of sentence type suggests a faster processing of the passives over the actives. In this segment, an interaction with Group is approaching significance, showing that the difference between the two sentences is mainly due to the children's group. We hypothesize that the effect in Segment 3 is a spill-over of the effect found in Segment 2.

In the RTs analysis, we also found an effect of Sentence type in Segment 5 , the location adjunct, with both adults and children reacting faster to SRs with actives than with passives. We interpret this as being a late effect due to the interpretation of passive morphology, that surfaces after the segments including the participle (is painting/is being painted), and the by-phrase (the elephant/by the elephant). For the effect in Segment 6, obtained with the analysis per item, we hypothesize that it is a spill-over of the effect in Segment 5. In the next section we compare passive SRs and ORs.

COMPARISON BETWEEN STUDY I AND 2

In the present section we compare the listening RTs for passive SRs and ORs. The aim is to observe whether there is a difference in the listening times 
TABLE 5. Mean RTs and Standard Deviation of children and adults for each sentence type

\begin{tabular}{llll}
\hline & & Children & Adults \\
\hline SR active & Mean & $293 \mathrm{I}$ & I220 \\
& SD & $9 \mathrm{IO}$ & $46 \mathrm{I}$ \\
SR passive & Mean & $289 \mathrm{I}$ & 993 \\
& SD & 992 & 470 \\
PP & Mean & $284 \mathrm{I}$ & $\mathrm{I} 272$ \\
& SD & 726 & 485 \\
PS & Mean & 2906 & I 1 I0 \\
& SD & 623 & $4 \mathrm{I} 5$ \\
SP & Mean & 2808 & $\mathrm{I} 329$ \\
& SD & 669 & 405 \\
SS & Mean & 2866 & I376 \\
& SD & 597 & 409 \\
\hline
\end{tabular}

for the different types of OR (match and mismatch of number features) and passive SRs. As mentioned in the 'Introduction', passive SRs and ORs are structurally different and a segment-by-segment comparison is not possible because the segments do not form minimal pairs. Instead, we conduct here a comparison of total RTs for the whole sentences to investigate the effects of overall complexity of the two types of sentence in children's and adults' on-line processing (see Rodhe \& Gibson, 2003, for a similar analysis).

\section{Passive SRs and ORs}

To calculate the RTs for the whole sentences (passive SRs and ORs with matching and mismatching number features), the average R'Ts of each segment were added and analyzed for each sentence type separately. Table 5 shows the RTs of the two groups in ms.

An ANOVA was used to compare passive SRs and ORs with either matching or mismatching number features, in children and adults, with Sentence type as a within-subjects factor and group as a between-subjects factor. Only an analysis by subject (FI) was conducted, due to the different number of items in the conditions.

The ANOVA revealed a main effect of Group $\left(F_{\mathrm{I}}(\mathrm{I}, 49)=87, \mathrm{I} 25\right.$, $\left.p<\cdot 000 \mathrm{I}, \eta p^{2}=\cdot 640\right)$, reflecting shorter RTs in adults compared to children, a main effect of Sentence type $\left(F_{\mathrm{I}}(\mathrm{I}, 49)=2,456, p<\cdot 047, \eta p^{2}=\cdot 048\right)$, and an interaction between Sentence type and $\operatorname{Group}\left(F_{\mathrm{I}}(\mathrm{I}, 49)=2,867\right.$, $\left.p<\cdot 024, \eta p^{2}=\cdot 055\right)$. The pairwise comparisons showed significantly shorter R'Ts for passive SRs compared to all four conditions with ORs (PP, $\mathrm{PS}, \mathrm{SP}, \mathrm{SS})$ in the adult group: passive SR and OR-PP $\left(F_{\mathrm{I}}(\mathrm{I}, \mathrm{I} 6)=\mathrm{I} 4,549\right.$, $\left.p<\cdot 002, \eta p^{2}=\cdot 476\right)$, passive $\mathrm{SR}$ and OR-PS $\left(F_{\mathrm{I}}(\mathrm{I}, \mathrm{I} 6)=23,34 \mathrm{I}, p<\cdot .00 \mathrm{I}\right.$, 
$\left.\eta p^{2}=\cdot 593\right), \quad$ passive $\mathrm{SR}$ and $\mathrm{OR}-\mathrm{SP} \quad\left(F_{\mathrm{I}}(\mathrm{I}, \mathrm{I} 6)=3 \mathrm{I}, 934, \quad p<\cdot 000 \mathrm{I}\right.$, $\left.\eta p^{2}=.666\right), \quad$ passive $\mathrm{SR}$ and OR-SS $\left(F_{\mathrm{I}}(\mathrm{I}, \mathrm{I} 6)=29,288, \quad p<\cdot 0 \circ \mathrm{OI}\right.$, $\left.\eta p^{2}=647\right)$. For the children's group, pairwise comparisons revealed no significant difference between the RTs of passive SRs and ORs with match or mismatch of number features.

\section{INTERIM DISCUSSION}

The analysis of total RTs revealed two main facts. First of all, children were significantly slower than adults, and their RTs for passive SRs and ORs did not show any significant difference. This result suggests that, although children process passive SRs and ORs similarly to adults, as shown by the segment-by-segment analysis in Studies I and 2, the automatization of their on-line processing is not yet adult-like, and no difference is detectable between passive SRs and ORs at age 6;OI-8; I I .

Second, the comparison between Studies I and 2 showed that adults had shorter RTs for passive SRs compared to ORs with matching or mismatching number features. This result is in line with Rodhe and Gibson (2003), in which passive SRs were processed more quickly than ORs by English-speaking adults in a self-paced reading task.

The adults' results confirm the hypothesis by Belletti (2009) and Contemori and Belletti (2013), according to which passive SRs display lower complexity due to the assumed derivation by SMUGGLING, and compared to ORs where intervention of the subject occurs.

\section{GENERAL DISCUSSION}

Two main results emerge from our studies. First of all, children's off-line comprehension is in line with the literature on ORs and (full-actional) passives, with children performing less accurately than adult participants on both structures. Second, as showed in the segment-by-segment results, the structures are processed in a similar way by children and adult participants, even though children's off-line comprehension is not yet adult-like.

In our studies, we also explored two novel morphological aspects of child processing: the role of number in long-distance dependencies and active vs. passive morphology in SRs. First, we manipulated the number properties of the subject/object DPs and verb in ORs, showing that a facilitation emerges for the two mismatch conditions (PS-SP) over the match condition. Our result on off-line comprehension is consistent with previous results by Adani (2008).

Adani (2008) tested centre-embedded clauses, which are generally assumed to be harder to parse than right-branching clauses (Chomsky, I957, r965; Chomsky \& Miller, r963), not only for adults but also for children (Corrêa, I 995 ; Kidd \& Bavin, 2002; a.o.). The effect of mismatch 
in our study suggests that children perform more accurately on the mismatch conditions (Adani, 2008), also in right-branching relative clauses with lower complexity. We observed that the facilitation effect is not reflected in children's on-line processing, as ORs with matching or mismatching number features are processed alike in children and adults. We adopt the approach by Friedmann et al. (2009) and Belletti et al. (2012) to account for the similarity in the on-line processing of the matching and mismatching in ORs. We speculate that the facilitation effect between the two conditions is a late effect that only occurs 'off-line'. As proposed by Friedmann et al., in ORs the intervention of the subject NP causes a disruption of the dependency between the head of the relative clause (i.e., the object NP) and its gap within the relative clause. Due to the disruption, children cannot always assign the theta roles of subject and object correctly (e.g., 'Who did what to whom?'), and as a result they perform less accurately than adults in off-line comprehension. In the mismatch compared to the match condition, children experience a lower level of difficulty, due to the difference in number features between the subject and object NPs (Belletti et al., 2012).

Analyses of RTs highlight an effect of plurality of the NPs in both groups of participants, with shorter RTs when a plural NP is encountered, compared to the conditions where the same NPs are in the singular. This result shows an on-line sensitivity to the marked form of the NP in both children and adults and is in line with previous studies employing agreement-error elicitation tasks with English-speaking adults (Bock \& Eberhard, I993; a.o.). Although plural NPs entail morphological number information, which should add complexity with respect to singular NPs (as also shown by the emergence of singulars before plurals in child speech, e.g., Brown, I973, among others), plural forms are not slower to process than singular ones.

In Study 2, off-line accuracy on active SRs is at ceiling level in both children and adults, whereas SRs with passives are still challenging for children aged 6 ;OI-8; I I. Nonetheless, for both types of SR, children's on-line processing at the age of $6 ; 0 \mathrm{I}-8$; I I mirrors that of adult participants, with only their overall speed of processing being significantly slower.

We found an effect of Sentence type in Segment 2 and 3, with shorter RTs for SRs with passives than SRs with actives. We speculated that the effect in Segment 2 might not be reliable. We hypothesized that the effect in Segment 3, mainly found in the children's group, might be a spill-over of the effect found in Segment 2.

We also obtained an effect of Sentence type in Segment 5 and 6, that we interpret as a manifestation of the thematic assignment. We hypothesize that both groups of participants process a SR with passives assigning the thematic role of Agent to the first NP. Then, when they encounter the 
segment with the passive verb and the $b y$-phrase, they make a reanalysis, assigning the thematic roles again, as shown by the higher RTs at the segment after the $b y$-phrase, compared to the active SR. However, the reanalysis is not always performed correctly by children, as their off-line accuracy in this condition is still lower than that of adult speakers, compared to the active counterpart.

Our data are not in line with the study of Stromswold et al. (2002), who argued that children interpret passives off-line, and confirm instead previous findings by Marinis (2007) and Marinis and Saddy (2013), showing that when children encounter the verb in the passive voice, their RTs increase, reflecting the process of reanalysis necessary to assign the correct thematic roles. The effect emerging in our study is delayed with respect to the results of Marinis, and Marinis and Saddy, in which passive sentences were slower after the verb. We speculate that the difference in the emergence of the effect is a result of the experimental material and design. First of all, in our design the sentences are embedded in a relative clause (e.g., ... that is being chased .../...that is chased ...), and hence are syntactically more complex than in Marinis, and Marinis and Saddy. Second, in our task, two pictures are shown at the same time and participants are asked to decide which one of the two matches the sentence. In Marinis, and Marinis and Saddy, only one picture was shown, that is in a match or mismatch with the sentence heard by the participant. The effect of passive morphology could emerge later than in Marinis, and Marinis and Saddy, as a result of the choice the participant has to make between the two pictures after hearing the sentence. Also, in Marinis, and Marinis and Saddy, the participant had time to see the picture before the sentence started and could develop some expectations, which would have to be revised in the mismatch condition as soon as the passive verb was heard (i.e., effect emerging on the verb and on the $b y$-phrase). In our design, we did not obtain any effect for the passive SRs on the passive verb and on the $b y$-phrase (Segments 3 and 4 , respectively). However, we obtained an effect on the adjuncts (i.e., Segments 5 and 6 ), which came after the critical segments that disambiguated for an active vs. passive interpretation. This was immediately before participants had to make a decision on which picture was correct. We speculate that the complexity of the sentences and the decision between the two pictures might have led to the later emergence of the effect compared to Marinis, and Marinis and Saddy. The effect in Segments 5 and 6 is likely to correspond to the disambiguation of the passive interpretation and the choice for the correct picture, as a result of the reassignment of the theta roles.

The off-line and on-line results also suggest that for children aged 6 ; I-8; I I, passives are still costly in terms of processing load compared to actives (due to the lower accuracy off-line), but the principles that drive their interpretation seem to be already in place, as demonstrated by 
the segment-by-segment RTs (i.e., similar underlying processing of the structure on-line in children and adults).

In the comparison between Studies I and 2, we compared the RTs for passive SRs and ORs to test the complexity of the two structures in the real-time processing of adults and children. The results for adults showed that RTs for passive SRs are shorter than those of ORs, independently of the matching or mismatching of number features of the OR. This supports the approach by Belletti (2009) and Contemori and Belletti (2013), according to which passive SRs display a lower level of complexity than ORs, where intervention of the subject in the filler-gap dependency occurs. The effect did not emerge in children, who were overall slower than adults. We speculate that the difference between children and adults is the result of the ongoing development of children's automatization of language processing.

The results of our studies and the interpretation given are compatible with a CONTINUITY view of language processing, according to which the parser is the same for children and adults and any performance difference results from other factors (Crain \& Wexler, I 999; Felser et al., 2003; Love, I 997; Roberts et al., 2007; a.o.). However, this does not exclude the possibility that the parser may be qualitatively different at earlier stages of language development. Similar studies with children younger than six are needed to verify this possibility.

\section{CONCLUSIONS}

Our examination of the processing of relative clauses in children supports the view that children from 6;0 to 8; I demonstrate the processing reflexes observed in adults. Even though children differ from adult speakers in their off-line accuracy (e.g., SRs with passives, ORs) and in the speed of processing (e.g., SR with passives), their processing systems are shown to be qualitatively similar.

In the study of relative clauses, we manipulated two main factors: the verbal morphology within the relative clause (active vs. passive) and the features that may contribute to the correct object interpretation (singular vs. plural). In both cases our findings are in line with the claims that children rely on syntactic structure in their on-line sentence processing (Felser et al., 2003; Love, I997; Roberts et al., 2007).

\section{REFERENCES}

Adani, F. (2008). The role of features in relative clause comprehension: a study of typical and atypical development. Unpublished $\mathrm{PhD}$ dissertation, University of Milano-Bicocca.

Adani, F., van der Lely, H. K. J., Forgiarini, M. \& Guasti, M. T. (20I0). Grammatical feature dissimilarities make relative clauses easier: a comprehension study with Italian children. Lingua r2o, 2 I 48-66. 
Arosio, F., Guasti, M. T. \& Stucchi, N. A. (201 I). Disambiguating information and memory resources in children's processing of Italian relative clauses. Fournal of Psycholinguistic Research 40(2), I 37-54.

Belletti, A. (2009). Notes on passive object relatives. In P. Svenonius (ed.), Functional structure from top to toe. Oxford: Oxford University Press.

Belletti, A. \& Contemori C. (2010). Intervention and attraction: on the production of subject and object relatives by Italian (young) children and adults. In J. Costa, A. Castro, M. Lobo \& F. Pratas (eds), Language acquisition and development 3, 39-52. Cambridge: Cambridge Scholars Press.

Belletti, A., Friedmann N., Brunato D. \& Rizzi L. (2012). Does gender make a difference? Comparing the effect of gender on children's comprehension of relative clauses in Hebrew and Italian. Lingua I22( ( о), 1053-69.

Bock, K. \& Eberhard, K. M. (I 993). The meaning, sound, and syntax of English number agreement. Language and Cognitive Processes 8, 57-99.

Borer, H. \& Wexler, K. (1987). The maturation of syntax. In T. Roeper \& E. Williams (eds), Parameter setting, I 23-72. Dordrecht: Reidel.

Brown, R. (1973). A first language. Cambridge, MA: Harvard University Press.

Chomsky, N. (1957). Syntactic structures. The Hague: Mouton.

Chomsky, N. (1965). Aspects of the theory of syntax. Cambridge, MA: MIT Press.

Chomsky, N. \& Miller, G. (1963). Introduction to the formal analysis of natural languages. In R. Luce, R. Bush \& E. Galanter (eds), Handbook of mathematical psychology, 269-32 I. New York: John Wiley.

Collins, C. (2005). A Smuggling approach to the passive in English. Syntax 8, 8I-I 20.

Contemori, C. \& Belletti, A. (20I3). Relatives and passive object relatives in Italian speaking children and adults: intervention in production and comprehension. Applied Psycholinguistics. doi: 10.1017/So142716412000689.

Correa, L. M. S. (1995). An alternative assessment of children's comprehension of relative clauses. Fournal of Psycholinguistic Research 24, $\mathrm{I}_{3} 3_{-203}$.

Crain, S. \& Thornton, R. (1998). Investigations in Universal Grammar: a guide to experiments on the acquisition of syntax and semantics, Cambridge, MA: MIT Press.

Crain, S. \& Wexler, K. (I 999). Methodology in the study of language acquisition: a modular approach. In W. C. Ritchie \& T. K. Bhatia (eds), Handbook of language acquisition, San Diego: Academic Press.

de Villiers, J., Tager-Flusberg, H., Hakuta, K. \& Cohen, M. (r979). Children's comprehension of relative clauses. Fournal of Psycholinguistic Research 8, 495-518.

Eberhard, K. M. (I 997). The marked effect of number on subject-verb agreement. Fournal of Memory and Language 36, 147-64.

Felser, C., Marinis, T. \& Clahsen, H. (2003). Children's processing of ambiguous sentences: a study of relative clause attachment. Language Acquisition I I(3), I 27-63.

Ferreira, F., Henderson, J. Anes, M., Weeks, P. \& McFarlane, D. (I996). Effects of lexical frequency and syntactic complexity in spoken language comprehension: evidence from the auditory moving window technique. Fournal of Experimental Psychology: Learning, Memory and Cognition 22, 324-35.

Fodor, J. D. (1998). Learning to parse? Fournal of Psycholinguistic Research 27, 285-319.

Fox, D. \& Grodzinsky, Y. (1998). Children's passive: a view from the by-phrase. Linguistic Inquiry 29, $3 \mathrm{I} \mathrm{I}-32$.

Friedmann, N., Belletti, A. \& Rizzi L. (2009). Relativized relatives: types of intervention in the acquisition of A-bar dependencies, Lingua II9(I), 67-88.

Friedmann, N. \& Novogrodsky, R. (2004). The acquisition of relative clause comprehension in Hebrew: a study of SLI and normal development. Fournal of Child Language 3I, 66 I-8I .

Gordon, P. C., Hendrick, R. \& Johnson, M. (200I). Memory interference during language processing. Fournal of Experimental Psychology: Learning, Memory and Cognition 27, I 4 I I -23 .

Gordon, P., Hendrick, R. \& Johnson, M. (2004). Effects of noun phrase type on sentence complexity. Fournal of Memory and Language 5I, 97-I I 4. 
Haskell, T. R. \& MacDonald, M. C. (2003). Conflicting cues and competition in subject-verb agreement. Fournal of Memory and Language 48, 760-78.

Hestvik, A., Schwartz, R., Tornyova L. \& Datta, H. (2005). Picture-naming shows children reactivate antecedents at trace positions. Poster presented at the Generative Approaches to Language Acquisition (GALA) Conference, Siena, Italy.

Horgan, D. (1 978). The development of the full passive. Fournal of Child Language 5, 65-80.

Jensen de Lopez, K. Sundahl Olsen, L. \& Chondrogianni, V. (20I2). Comprehension and production of relative clauses in Danish typically developing children and children with SLI. Fournal of Child Language. doi: http://dx.doi.org/10. I0I 7/So30500091 20005 I 7.

Kidd, E. \& Bavin, E. L. (2002). English-speaking children's comprehension of relative clauses: evidence for general-cognitive and language-specific constraints on development. Fournal of Psycholinguistic Research 3i(6), 599-6 I 7.

Labelle, M. (I990). Predication, wh-movement, and the development of relative clauses. Language Acquisition I, 95-I 19.

Love, T. (I 997). The processing of non-canonically ordered constituents in long distance dependencies by pre-school children: a real-time investigation. Fournal of Psycholinguistic Research 36, I9I-206.

Mak, W. M., Vonk, W. \& Schriefers, H. (2002). The influence of animacy on relative clause processing. Fournal of Memory and Language 47(I), 50-68.

Mak, W. M., Vonk, W. \& Schriefers, H. (2006). Animacy in processing relative clauses: the hikers that rocks crush. Fournal of Memory and Language 54(4), 466-9o.

Maratsos, M., Fox, D., Becker, J. \& Chalkley, M. (1985). Semantic restrictions on children's passives. Cognition 19, 67-I 9 I.

Marinis, T. (2007). On-line processing of passives in Li and L2 children. In A. Belikova, L. Meroni \& M. Umeda (eds), Proceedings of the and Conference on Generative Approaches to Language Acquisition North America (GALANA), 265-76. Somerville, MA: Cascadilla Proceedings Project.

Marinis, T. (2010). On-line sentence processing methods in typical and atypical populations. In S. Unsworth \& E. Blom (eds.), Experimental methods in language acquisition research, I39-62. Amsterdam: John Benjamins.

Marinis, T. \& Saddy, D. (2013). Parsing the passive: comparing children with Specific Language Impairment to sequential bilingual children. Language Acquisition 2o(2), I 55-79.

Ratcliff, R. (I993). Methods for dealing with reaction time outliers. Psychological Bulletin II4(3), $5 \mathrm{IO}-32$.

Rizzi, L. (1990). Relativized Minimality. Cambridge, MA: MIT Press.

Roberts, L., Marinis, T., Felser, C. \& Clahsen, H. (2007). Antecedent priming at trace positions in children's sentence processing. Fournal of Psycholinguistic Research 36(2), I 75-88.

Rohde, D. \& Gibson, E. (2003). The on-line processing of active and passive structures in English. Paper presented at CUNY Conference 2003.

Sheldon, A. (1974). The role of parallel function in the acquisition of relative clauses in English. Fournal of Verbal Learning and Verbal Behavior 13, 272-8 I.

Sheldon, A. (1977). On strategies for processing relative clauses: a comparison of children and adults. Fournal of Psycholinguistic Research 6, 305-1 8.

Stromswold, K, Eisenband, J., Norland, E. \& Ratzan, J. (2002). Tracking the acquisition \& processing of English passives: using acoustic cues to disambiguate actives \& passives. Paper presented at CUNY Conference on Sentence Processing 2002.

Sudhalter, V. \& Braine, M. (I985). How does comprehension of passives develop? A comparison of actional and experiential verbs. Fournal of Child Language 12, 455-70.

Tavakolian, S. L. (I98I). The conjoined-clause analysis of relative clauses. In S. L. Tavakolian (ed.), Language acquisition and linguistic theory, I67-87. Cambridge, MA: MIT Press.

Traxler, M. (2002). Plausibility and subcategorization preference in children's processing of temporarily ambiguous sentences: evidence from self-paced reading. Quarterly Fournal of Experimental Psychology 55(I), 75-96. 
Warren, T. \& Gibson, E. (2002). The influence of referential processing on sentence complexity. Cognition 85, 79-I I 2.

Warren, T. \& Gibson, E. (2005). Effects of NP-type on reading English clefts. Language and Cognitive Processes $20(6), 75 \mathrm{I}-67$.

Wilson, M. (I988). MRC psycholinguistic database: Machine-usable dictionary, version 2.00. Behavior Research Methods, Instruments, and Computers 2o, 6-Iо. 